\section{COVID-19 and Mental health in School-Aged Children and Young People: Thinking ahead while preparing the return to school and to life "as usual"}

\author{
Margarida Gaspar de Matos ${ }^{1,2}$, Tony Wainwright ${ }^{3}$ \\ ${ }^{1}$ Projeto Aventura Social, Faculdade de Motricidade Humana, Universidade de Lisboa, Lisboa, Portugal \\ 2 Instituto de Saúde Ambiental, Faculdade de Medicina da Universidade de Lisboa, Lisboa, Portugal \\ 3 University of Exeter
}

Corresponding author: Margarida Gaspar de Matos I mmatos@fmh.ulisboa.pt
Received:

11 March 2021

Last revised:

21 April 2021

Accepted:

27 April 2021

\begin{abstract}
From December 2019 onwards, the COVID-19 pandemic brought with it several health, social and economic issues, particularly associated with home confinement measures, lockdown, and fear of being infected or otherwise affected by the virus, or even die. As with everybody else, children and young people are experiencing a new reality. The question is how well, and how long will it take for recovery. Furthermore, what is the likely affective, social, academic and economic cost for this recovery. There are at least four psychosocial scenarios that must be separately analysed: children and young people with previous mental ill health that may be left unattended by health services; those who may have a first episode of mental ill health during home confinement and had no health care; those with psychosocial vulnerabilities that may be left under-monitored and exposed to undermining circumstances, and finally those that have faced a huge change in their routines and may have formed a relatively stable pessimistic outlook that affects their wellbeing. Social isolation and quarantine have precipitated a decrease in wellbeing and an increase in mental health problems and psychosocial vulnerabilities, plus a lowering of general capacity for health, education and social security care. Confined children and young people are separated from their usual social support, deprived of the personal freedom that they are used to, and see a comprehensive change in the usual life routine and lifestyle with an enormous change in physical, social, affective and even digital environments. All children and young people are in need of a monitoring system and of arrangements to promote social participation and engagement, that runs at the same time as their return to school. Mitigating negative mental health effects requires a concerted effort from the general population, policy makers, education and healthcare professionals. Moreover, international health and educational organisations have advised governments that this action would benefit by being proactive: meaning there is an urgent need to get ready immediately - being ready for the "day after", thinking ahead and being able to put together in the field and on time, an adequate nation-wide, participatory, multidisciplinary, mental health related set of interventions.
\end{abstract}

Keywords: COVID-19, Social isolation, Home confinement, Wellbeing, Mental health, Mental ill health, School, Children, Adolescents, Young people.

\section{The COVID-19 pandemic}

The "Global Standards for Health Promoting Schools" released by WHO and UNESCO (WHO, 2018) in September 2020 is in the process of broad implementation (WHO, 2020a, 2020b) and in several countries will be a joint project between government health and education authorities and also local government, given the impact of the pandemic on regional and local communities. One of the recommendations is that National Governments create a National Plan for Education, Health Promotion and Children at a risk Monitoring, ready to act when necessary, particularly in the area of virtually delivered 
educational provision. The current COVID-19 pandemic has surprised the world despite many warnings (Rosling, Rosling, \& Ronnlund, 2018), but governments now must be prepared for a "next time", foreseeing scenarios and preventing undermining future situations (Christakis, Cleve, \& Zimmerman, 2020; Dratva et al., 2020; Lee, Cadigan, \& Rhew, 2020; Loades et al., 2020).

From December 2019 onwards, the COVID-19 pandemic brought several health, social and economic issues, particularly associated with social confinement measures, lockdown, and fear of being infected or affected by the virus, or even die. As with everybody else, children and young people are experiencing this new reality; however, for them, especially the younger ones, everything is rather new anyhow. Therefore, it is expected that they may adapt and adjust easier than adults, although it might crucially depend on the context.

Even if infants, children and young people are only indirectly affected by COVID-19 and even if they experience the infection or its sequelae in a less severe way, they will all have been affected by the uncertainty, with disrupted routines; at home with the parents and siblings; away from school, peers, and out of school activities. It is plausible that the consequences for a young person will be greater if they are close to one of these contemporary hazards; those that were infected (and how bad was the infection) and affected (and how bad and what kind of effect) (UNICEF, 2020b; UNICEF 2020c; Kowal et al., 2020; Singh et al., 2020) and, besides health matters, the socioeconomic impact: jobs, money, workload, perceived and actual risks at work (Javed, Sarwer, Soto, \& Mashwani, 2020; Ciampo \& Ciampo, 2021). Analysing the needs of children and young people and the mental health support to be provided in the present and in a near future is the aim of this paper.

\section{Epidemiological evidence}

Liu, Bao, Huang, Shi, and Lu (2020) stressed that children who were hospitalized after contracting COVID19 , with the associated infection control-related separation measures in place, require special attention: children infected or suspected of being infected with the virus who are quarantined in local hospitals, children whose caregivers are infected in quarantine or hospitalized, or children whose caregivers have died from the disease. These children might be more susceptible to mental health problems because of their greater fear of infection or due to the grief caused by parental loss or separation. Social and family support is essential for children's psychological development, and wellbeing and separation from caregivers pushes children into a state of crisis and might increase the risk of psychological disorders.

Brooks et al. (2020) carried out a systematic review of the psychological impact of quarantine on general adult population. Twenty-four papers met their inclusion criteria. Most reviewed studies reported negative psychological effects including post-traumatic stress symptoms, confusion, and anger. Stressors included longer quarantine duration, infection fears, frustration, boredom, inadequate supplies, inadequate information, financial loss, and stigma.

In another related study, Viner et al. (2020) conducted a review showing the undermining effects of social isolation and quarantine in children and adolescents and urged governments to limit school closure to a minimum, plus trying alternative innovative ways of managing the physical and social school environment as an alternative to total closure.

Furthermore, young people may experience social confinement differently, and in different ways across pandemic waves (Matos, 2021; Munro \& Faust, 2021). At least one study carried out in Portugal, found that a kind of ego depletion can emerge, related to pandemic fatigue as children and adolescents experience successive waves of COVID-19 (Matos, 2021).

Loades et al. (2020) did a rapid systematic review on the impact of social isolation and loneliness on the mental health of children and adolescents ( 83 articles were included), and they concluded that children and adolescents tend to present higher rates of depression and anxiety after social isolation, and that the duration of loneliness was more strongly related to mental health symptoms than the intensity of loneliness. A 
national Portuguese survey with children and adolescents has described some of them to feel bored (54\%), worried about grandparents $(53,8 \%)$, parents $(45,3 \%)$, other relatives (41.4\%), and friends (40,3\%), with $9,8 \%$ presenting more anxiety symptoms than national normative data (Salvaterra \& Chora, 2021).

An international study including Portugal, Italy and Spain (3-18 years old) reported that, among Portuguese children, $25 \%$ had symptoms of anxiety and 8.5\% symptoms of depression (Orgilés et al., 2021). Another study also based in Portugal, Italy and Spain (3-18 years old) has reported that more than $50 \%$ of the children feel bored and $40 \%$ irritable, 1 out of 3 lonely, nervous, worried and anxious (Francisco et al., 2020). Furthermore, they reported that children and adolescents have been exposed to three times more screen time and also reduced their physical activity by the half (from 30-60 min to $30 \mathrm{~min}$ ) during the lockdown (Francisco et al., 2020).

The project Save The Children got respondents from 37 countries, with 17565 parents/carers and 8069 children (not including Portugal) (Ritz, O'Hare, \& Burgess, 2020). More than half the children that could not see friends because of the social confinement declared to feel less happy (57\%), more worried (53\%), less safe $(58 \%)$, and $83 \%$ reported an increase of negative feelings, compared to the period before interruption of formal education. Children also reported an increase in family violence ( $9 \%$ increase) when schools are closed, and $89 \%$ of parents reported negative emotions, attributed to the pandemic, one out of five parents reported increasing use of negative parenting strategies (Ritz et al., 2020).

In the UK, a study from the National Health Service (NHS) reported that 1 out of 6 children and adolescents between 5 and 16 are likely to be suffering from a mental health problem ( $22 \%$ female adolescents and $13 \%$ male adolescents). The majority of those reporting a mental health problem (69.6\%) reported also a sleep problem (Vizard et al., 2020).

A study by UNICEF, developed during the lockdown period and including 8444 adolescents, aged 13 to 29 years old in Latin America and the Caribbean, has reported that $27 \%$ of adolescents feel symptoms of anxiety and $15 \%$ symptoms of depression (UNICEF, 2020a), 50\% feel less motivated to do activities that used to give pleasure and $43 \%$ of female adolescents and $31 \%$ of male adolescents feel pessimistic towards the future (UNICEF, 2020a). Three out of four adolescents felt the need to ask for physical or psychological support, but two out of five did not (UNICEF, 2020a). In Portugal, $10.8 \%$ parents report moderate to very severe symptoms of anxiety and $10.2 \%$ moderate to very severe symptoms of depression (Salvaterra \& Chora, 2021).

A recent study (Almeida et al., 2020) of Portuguese adults gives a clear picture of how families, teachers, medical doctors, nurses, and psychologists are coping with the pandemic. This data is relevant for the present analysis, because these adults are the parents, relatives, health providers and teachers of children and young people. It included 6079 Portuguese adults, and reported that $27 \%$ show symptoms of anxiety, $26,4 \%$ symptoms of depression and $26 \%$ symptoms of post-traumatic stress disorders, much higher than in a previous population study that was conducted in 2013 (Caldas de Almeida et al., 2013). Being a woman and having between 18 and 29 years old, being unemployed and economically low income, is the profile increasing psychological suffering. Major complaints include difficulties with work-life balance and lack of social and familiar support. Having a hobby, having a daily routine and practising physical activity are, on the other hand, associated with thriving. According to this same study, about one third of the respondents were high on resilience especially men (over 50), those who are employed and those who are retired.

Another study of the Portuguese adult population (Paulino et al., 2021) has reported that $70 \%$ of the population who quarantined or self-isolated reported moderate psychological difficulties, and $50 \%$ reported psychological suffering. Furthermore, regarding those who contracted COVID-19, 7 out of 10 reported psychological suffering and more than $50 \%$ show signs of moderate to severe depression. Of those with COVID19 who were admitted to hospital, $92 \%$ reported moderate to severe anxiety. 
In summary, COVID-19 and its associated public health measures - social isolation and quarantine - have precipitated symptoms of mood disorders and symptoms of anxiety. This result was to be expected since being separated from their loved ones, deprived of usual freedoms, and disruption of lifes' routines are likely to be experienced as highly stressful. With these changes in lifestyle, there is also highly probable wide-ranging changes in the physical, social, affective and digital environments. This can contribute to frustration, boredom, low mood, and, potentially, depression. Anxiety might arise from fear of infection and also from unclear messages about social distancing, often made worse by some media sources, increasing confusion, fear or even panic. Those with pre-existing mental illness might suffer from limited interpersonal interactions that are central to their management, as well as reduced access to helpful but "non-essential" (and thus often cancelled) psychiatric and psychology services (Venkatesh \& Edirappuli, 2020).

\section{Impact on the mental health and well- being of children and young people during the pandemic: "transactional ages" and diverse scenarios of home confinement}

It is now clear that everybody world-wide has been affected directly or indirectly by this pandemic. However, it is plausible that for those going through specific developmental life transitions, the challenge can be even bigger. Such transitions might include: beginning pre-school, beginning school, changing school, pubertal body changes, going to the university. These situations normally involve life changes that cause stress and mobilise extra strength and energy, even if these periods are experienced as positive life events. However, during a pandemic, these "extra-changes" are extra challenges that can jeopardise coping capacities and undermine wellbeing and health (Matos, 2020a).

Liu et al. (2020), in a study with young people, has described "symptoms" that may vary with age, some of these include crying, calling for attention, getting the "blues", showing worry, difficulties with concentration and attention. Some of the young people report not liking anymore what they used to love in the past, physical aches and pains and headache. Liu et al. (2020) also reported frequent changes in eating and sleep habits, with difficulty sleeping and loss of appetite.

Concentrating on children and young people and focusing on the mental health arena, it is useful to foresee at least four scenarios implying different challenges to children and young people coping with home confinement.

One is related to episodes of mental ill health that may appear, such as first psychotic episodes, anxiety disorders, mood disorders, developmental problems, behavioural problems, eating disorders, autism spectrum, substance use, delinquency, violence or cyberviolence (Mental Health Foundation, 2020; Fancourt, Steptoe, \& Bu, 2020; Flugharty \& Fancourt, 2021; Bu, Steptoe, \& Fancourt, 2021; Loades et al, 2020). Several researchers point out that mental distress, or feeling of unwellness, loneliness and/or despair have increased with the pandemic (Liu et al., 2020; Zhou et al., 2020; Lee et al., 2020). However, there are already data that suggest that this may not always be the case (Shevlin et al., 2020), suggesting a moderate impact of the pandemic on children and young people's mental health.

Besides mental ill health, a second scenario is where the lack of continued mental health care may result in people with pre-existing mental health conditions becoming more unwell, given that medical and psychological care is discontinued or not so present in children and young people's lives (Zhou et al., 2020; Junior, Gaulac, Andrade, \& Amaral, 2021).

Also, as a third scenario, there are a lot of situations that present psychosocial risks particularly impacting vulnerable people, as for instance family exposure to violence or abuse, family exposure to mental ill health, namely substance use. Furthermore, exposure to hunger or economic vulnerabilities, that with home confinement may be exacerbated, and lack of proper monitoring from social security offices, are also major 
risk factors (Lee et al., 2020; Matos et al., 2021; Francisco et al., 2020).

Another final scenario focuses not exactly on mental ill health but on mental health, wellness and mental wellbeing. High-risk situations may be created by changes in people's usual routines either in the family, in school or in the peer group. This will be made more difficult by uncertainty and fear of the future. After a six-months period of social isolation, studies have found psychological manifestations ranging from mild symptoms such as boredom, inattention, irritability, fatigue and excessive worries, to more severe manifestations, like worse cognitive performance, anxiety and depression (Ciampo \& Ciampo, 2021; Javed et al., 2020; Lee et al., 2020; Loades et al., 2020).

For children and young people, where a major part of their lives involves socializing with peers and gathering social experiences that may last a lifetime, the consequences of social distance and home confinement are highly predicable and have been confirmed by several studies (Brooks et al., 2020; Tomé, Branquinho, Cerqueira \& Matos, 2020; Lee et al., 2020; Loades et al., 2020; Kowal et al., 2020; Singh et al., 2020; UNICEF, 2020b; UNICEF, 2020c). Even when young people survive without direct physical or mental health consequences, existential problems may arise creating disorganization in younger ones and a lower sense of purpose; for young people it may be difficult making sense of their lives, together with a sense of boredom and loneliness (Matos, 2020a; Brooks et al., 2020).

The connection that children and young people keep with their families, with their schools and with their health care systems can also be complicated by the fact that adult caregivers, either parents' or health and educational professionals, are also often exhausted and under stress during lockdown (Almeida et al., 2020; Paulino et al., 2021).

We should also be aware (as has happened in the past with AIDS) that there is stigma that may affect young people who had to quarantine or became infected (in the "blame the victim" manner) (Bagcchi, 2020; Reis,
Ramiro, Matos, \& Diniz, 2013; Ramiro, Reis, Matos, \& Diniz, 2014).

Children and young people are in need of a monitoring system and other proactive arrangements to promote participation that runs concurrently with their return to school: first of all, we must listen to them and help them to make sense of this period of their lives; then supporting them in dealing with troubling emotions, feelings of fear, loss, lack of confidence, mistrust, social isolation. Then, developing routines (perhaps they need new routines), school routines, leisure routines, family routines. And, finally addressing the issues surrounding academic knowledge (and that should be the order of priority) (Matos et al., 2021; Dratva et al., 2020).

\section{Wellbeing and life experiences of chil- dren and young people under home confinement}

Within the context of the youth-led national project Dream Teens (https://dreamteens.aventurasocial.com/, a youth participative intervention project), Branquinho, Kelly, Arevalo, Santos, \& Matos (2020) did a survey among adolescents and young people (age range 16 to 24). It was an online survey disseminated by young people among their peers, in the context of their youth-led initiative. There were 617 respondents. They were asked about how they were experiencing home confinement that had been made compulsory with the first lockdown. At the first lockdown, they missed friends and their schools. They missed outdoor activities and sports. But they were happy about being more autonomous, less exhausted as they didn't have so many regular classes, thus a reduced school workload and consequent lower stress. Young people also found that teachers need to be trained in online education. Another key opinion was that primary health care services should change in order to be more effective in the future, to cope with probable future pandemics where new approaches, for example remote consultations, will be again necessary (Branquinho et al., 2020). Another pioneer study involving young people social participation also 
has stressed the relevance of inquiring young people and considering their needs and suggestions ( $O$ 'Sullivan et al., 2021). But when Portuguese young people returned to school (2020/2021 academic year), even if they were thrilled to get back to school routines and friends, they mostly found school disappointing, perhaps because school itself was never at the centre of their interest (Gaspar, Tomé, Ramiro, Almeida, \& Matos, 2020; Matos \& Aventura Social, 2018; Matos et al., 2017).

Another study, within the same Dream Teens project, has surveyed 304 young people aged 16 to 24, who were returning to school in the current academic year (Branquinho et al., in prep), by means of another online survey inquiring about how it was to be back to school. Students reported that they were confronted with returning to school, but not to their "cosy old school", as expected, but, instead, as if it was "another school", safe but cold and distant, indeed where students level of trust was markedly affected, particularly regarding the risks to their health and lifestyle. However, they were especially happy about being able to get out of home, and to practise outdoor activities, even if all those where subject to constraining (different) rules, to ensure adequate infection control. They found that teachers were too focused on academic remediation and ways of undertaking evaluations; a social environment of fear of infection, with several local procedures in school to avoid infection: gel, masks, physical distance, separated turns in school with smaller concentration of students during the breaks, forbidden to stay in school after classes, sometimes mixed methods - one week online, one week in school.

Many parts of the world then experienced a second and a third pandemic wave that, in some countries, including Portugal, had a much more devastating health and survival impact than the first wave and another lockdown was declared in several countries in a more or less restrictive way. During a focus group designed to analyse the effect of the pandemic upon sub-25 years old students (Matos, 2021), students have reflected that this new home confinement was felt and lived in a different way. If during the first one, after a few days of surprise, young people in general activated themselves in order to cope and adapt to school, family new routine, friends' separation, leisure interruption, during the second lockdown they felt just like they were accommodating to a new, slow, home-based and lonely life, turning "on" the survival button and only thinking of letting the days go (Matos, 2021). They have described how pandemic fatigue took them and how they no longer feel to have enough energy to get motivate for more than a "cruise speed". A few of them have mentioned moving towards individualism as they gave up searching for others and socialization spots and funny events "at distance", just for the pleasure, as if they were getting used to being alone; getting stuck on screen-time, getting "stuck" waiting. During this focus group, they mentioned that some university students went back to their parents' homes during their school year, and this fact implies that students, who had gained their autonomy from parental monitoring, are now back to a more dependent state of "parental monitoring". This can impose a severe lack of freedom and privacy. Some young people commented that the time they spend studying did not change after lockdown, but that during lockdown, they had extra challenges to cope with. These included planning their daily agenda, which forced them to become more autonomous and better organized than before (and also forced the parents of the younger ones to assist them with organising their schedules).

Remote delivery of classes from home, and where universities began to use podcasts and streamed material that could be listened to or viewed later, included very large volumes of information and required some discipline to keep up. Otherwise, students find themselves unable to catch up, missing significant lectures and classes (Schwegler, 2020; Branquinho et al. in prep). For everyone, students and other persons working with a telework basis, during lockdown, working hours, leisure time, weekdays and weekends are reported to blend into each other. The coexistence of several activities in a person's own home lends everyday life an apparent lack of variety, and steals the "sense of time", and blurs the sense of "identity" (Matos, 2021). Some young people say that they now prefer casual/comfortable clothes, and that they have 
become trendy, while some other students reporting to prefer to get ready to go out, street shoes included. Privileging comfort and cosiness can be an asset, but in the long run can also mean the loss of a cared selfimage. Some young people report that while clothes shops are still closed, they have grown so much that they do not have proper clothes to wear. Others put on weight and share the same problem.

Also, during lockdowns, home circumstances have generally led to different leisure and work conditions. For many, it can be that everybody is in the same living room at the same time, sharing one computer and the TV, with all the attendant noise, discussion, conflict and lack of proper concentration and privacy. However, it can also be a private comfortable place with equipment for everybody and sufficient space for people to have some time away from each other. These two versions of lockdown have very different implications for stress and mental health.

The best solution found was when everybody has one's own place and when they can have periods when they are together and periods when they are away from each other (Matos 2020a), avoiding being in the same room all day, all week, working, sleeping, screen-time spending, eating, etc. Some youngsters have tried establishing routines for working/studying, walking the dog, cooking, eating, exercising, checking social media, contacting friends, listening to music, playing an instrument, reading: "There are even apps to tell you must stand up and walk, or that you must rest your eyes and look away from screen. Other apps tell you how to party with friends just like 'if it is a Friday'”' (Matos, 2021).

From a social point of view there is an accumulation of "lost" life experiences that will never come back: graduation party, graduation holidays, Erasmus, sabbatical year (Matos, 2021), and they say that the present, the daily experience of this pandemic and home confinement would be much more bearable if only they could foresee the future. For them, the worst problem was not to coping with the present situation but with the uncertainty of when, and how this is going to end, and what will be next.
Older adolescents and university students have mentioned the disturbance regarding their expected first seduction, sexual and love experiences, that usually come casually along with the school environment and related socialization arenas. They also talk about all the infection risks with a new partner, out of the "family bubble", and the risks of dating a potential partner who will also not be in the "family bubble".

In this connection, COVID tests can be a problem: tests were meant for surveillance and control of the pandemic, to screen, detect, isolate and prevent virus transmission. They were not meant as a "certificate of health" and they do not work that way. The results of a test can be hours away, and false positives and negatives are difficult for people to grasp. Having had a "recent" negative test can give a false sense of security while meeting new people who newly tested negative and are asymptomatic, but nevertheless infectious and infecting.

Several studies have been published during the last year, including some systematic reviews or brief reviews (Nearchou, Flinn, Niland, Subramanian, \& Hennessy, 2020; Jansen et al., 2020; Liu et al., 2020; Brooks et al., 2020; Loades et al., 2020; Ciampo \& Ciampo, 2021) and results are consistent with this fourfold view of young people's home confinement situations: the need to preserve wellbeing, the need to adequate prevention and care of previous mental diseases, the need to prevent and care for those having a first episode of mental illness, and the need for adequate psychosocial interventions.

\section{Foreseeing and thinking ahead about the "day after", and planning the return to school and to life "as usual"}

Social and environmental challenges can be considered a real opportunity for social transformation. COVID-19 is the first major pandemic of the current half century, and most probably will not be the last. We therefore can learn to be more proactive and develop more effective approaches: to seek the hidden opportunities and to reflect and react as a global society using a public health (including public 
mental health) focus. Regardless of where people are living in the world or their ethnic group, gender, age, or socioeconomic status, they all experience the same COVID-19 disease (although with the usual bias and the usual inequities). Perhaps, as stated by Ahmad, Mueller, and Tsamakis (2020) this gave a unique chance to bring people of all cultures together and reduce prejudice and stigma because of the global nature of COVID-19.

COVID-19 is challenging people's position in the world because it gives a real and concrete sense of globalization and connectedness, regardless of geographic and cultural distance, while at the same time needing to keep our individuality because the illness is a threat to our physical, and mental, wellbeing. By merging public health with mental health, the ways that COVID-19 is changing the world could be better used to protect and promote population wellbeing, as pointed out by WHO (2020a; https://www.who.int/health-topics/mental-health\#tab=tab 1).

In considering the future, Liu et al., (2020) have recommend that we can learn from the Chinese experience after the first wave in Wuhan, where they developed a plan to address the needs of children and young people who had contracted COVID-19, and of those affected in other ways. The plan included support from nutritionists, mental health and physical education professionals talking to children and young people. It involved getting children in hospital-care talking regularly to parents and seeing them on videoconferences and having volunteers with these children and adolescents after discharge from hospital, if parents were not available. At a global level, it also included providing a regular screening procedure, and preventive and promotional interventions in schools, mostly based in social emotional competences and self-regulation, and adequate mental health care and support. Liu and al. (2020) report that this improved health care through collaborative networks have been established nationwide and consist of psychiatrists, psychologists, researchers, and community volunteers. Additionally, the post-pandemic surveillance of mental health among these children should be considered as it may not be a smooth transition either to old routines, to altered routines or even totally different routines.

The impact of COVID-19 created a temporary setback in promoting equity in general, by accentuating inequalities (socioeconomic, access to educational resources and health), as well as a temporary setback in the enhancement of affective and social environments in schools. Intervention strategies with young people must address not only academic matters but psychological and emotional and social issues like loneliness and feelings of poor social support (Lee et al., 2020).

It is now clear that there is a need for a specific group of educational and health professionals to redesign the future of education, to think about the "day after", so that children and young people can find their way out of home confinement and back to school with maximum wellbeing and mental health. It is now time to consider different possible future scenarios where people have different needs, and to suggest ways of addressing them. We need to avoid a "fear/ defensive" register or a passive, apathetic, depressive register and try to find flexible, open and innovative ways of coping, thriving and keeping wellbeing and mental health (Matos, 2020a).

Children and young people have responded differently to the pandemic and have experienced a wide diversity of life changes. Any future plans must take into account that there is no 'one size fits all' solution. Likely areas for focus include:

1) physical health problems - either in situations associated with COVID-19 or its sequelae, or in other health situations that were neglected and lacked adequate health care because of the impact of the pandemic;

2) mental health problems - in situations of mourning or trauma associated with the pandemic; mental health problems associated with fatigue associated with pandemic; new or previous mental health problem not adequately managed due to lack of regular mental health care;

3) wellbeing - at the level of increasing and promoting safety, trust and wellbeing of all inhabitants 
of the family, of the community and of the school ecosystems: students, teachers and other professionals;

4) socioemotional learning - students were affected in many different ways by COVID-19, they will undoubtedly have been affected; so, efforts will be needed to help them talk about their experiences, social interactions, and what they have learned from their experiences;

5) academic learning - students had different access and motivations to learn, in view of the changes of the last pandemic year;

6) economic impact - families (and the country, in general) may enter in impoverishment, associated with the pandemic;

7) social impact - the pandemic has put everyone in an abnormal social situation.

\section{Take-home messages}

Under the conditions people have been experiencing, it is a natural reaction that many will be bored, irritable, tired, hopeless and with low mood. People are not happy. This is not a nice circumstance. Under such pervasive conditions, curiosity, flexibility and openness are personal skills that are important for health maintenance and for promoting personal wellbeing and mental health. They are also useful skills to encourage, and their promotion should be included in educational programs at a school level (Matos, 2020b).

A few students will experience it all as an exciting challenge and thrilled to move forward; others will be waiting and watching quite fearfully the next steps; others will be in a reactive mode, irritable, anxious, angry, depressed, traumatized. Living permanently with fear does not lead to better protection but to a dissociation and lack of investment that may harm a whole generation left with permanent emotional, cognitive, behavioural and social problems.

There is no 'magic bullet' here, no 'one size fits all' solution. However, universal interventions adopting a "whole school participatory approach" have been found to be the most efficient and effective approach
(Tomé, Almeida, Ramiro, Gaspar, \& Matos, 2020; Matos et al., 2021; Loades et al., 2020; Lee et al., 2020; Ciampo \& Ciampo, 2021).

Special care needs to be given to vulnerable groups, including girls, minorities, people with chronic health conditions, children and young people with special educational needs, those with psychosocial vulnerability and associated risk, and those in poverty and experiencing food insecurity. Special attention should also be given to the potential for new technologies of information and communication (NTIC) and how they may provide some useful approaches to educational, health and social care. However, it is important to keep in mind that NTIC will not 'cure' inequality and that, indeed, access to NTIC is one aspect of this (the so-called 'digital divide').

Special attention to unmet needs among young people is related to substance use and other addictions (for example gambling), that may have been discontinued during confinement but may become a serious problem in the aftermath. Schools need to urgently innovate to better support students as we come out of this pandemic, in a way that looks to the future, as this can make a difference (Aventura Social, 2020a, 2020b; Matos et al., 2021). The focus is looking ahead and foreseeing new directions and adaptations for school, family and community environments that may lead to permanent post-COVID multidisciplinary professional support that can offer a wide range of sustainable interventions from population studies to classroom screening and monitoring, from promotional programs, to counselling, to formal psychotherapy. This will be a lifetime challenge for psychologists. Public campaigns with effective media involvement may help to promote mental and physical wellbeing of the populations by means of clear messages targeting personal and social development, emotional self-regulation, socioemotional competences, social cohesion, social active involvement and participation. This focus will be particularly important for children and young people, directly or through their families, their teachers and/or their healthcare providers (Tomé, Matos, Gomes, Camacho, \& Gaspar, 2017; Gaspar, Cerqueira, Branquinho, \& Matos, 2018; Matos et al., 2017). 


\section{National educational and health pro- moting strategies for an uncertain future}

Appeals to altruism, by reminding the public about the benefits of social confinement to wider society, can be favourable (Brooks et al., 2020). According to behavioural design theories, this approach will be effective alongside accurate information about the benefits of quarantine and/or social confinement but also with clear guidelines about what to do to minimise psychological problems and maximize wellbeing (Fogg, 2019).

Pandemics can undermine societies. The challenges are complex, and citizens are asked to follow rules that look erratic and change quickly and may make no sense. If the population are not aware of what is going on, they will not trust the government or its institutions, a precondition for compliance. The evidence suggests that authorities need to clearly inform, make the messages simple and stable but explain complexity when necessary, build trust and social cohesion, and build coping skills, self-regulation, problem-solving, team working and resilience skills. In a period, such as the one the world is facing, there is the need to 'user friendly' public policies and good support systems to promote healthy behavioural change (besides strong professional teams devoted to maintaining and improving the population's health and wellbeing). This can be done by increasing the availability of peoplefocussed physical and social supportive environments, for instance through a wider use of wellbeing nudging (Thaler \& Sunstein 2008), and social cohesion, social trust and community involvement, all the time being aware of what works and what doesn't (Szaszi, Palinkas, Palfi, Szollosi, \& Aczel, 2018).

All this means taking a public mental health perspective, embracing community participation, support and cohesion, in order to increase the odds among children and young people of learning and thriving with this experience, instead of getting stuck, mentally unwell, feeling hopeless and out of energy.

There is an urgent need to plan for future education, protection and wellbeing promotion of children and young people and also for increase self-empowering strategies to promote wellbeing and mental health, academic participation and active social involvement. No need for catastrophizing. Just making sure we do not miss the train.

\section{References}

Ahmad, A., Mueller, C., \& Tsamakis, K. (2020). COVID-19 pandemic: a public and global mental health opportunity for social transformation?. British Medical Journal, 369, m1383. https://doi.org/10.1136/bmj.m1383.

Almeida, T., Heitor, M., Santos, O., Costa, A., Virgolino, A., Rasga, C., Martiniano, H., \& Vicente, A. (2020). Relatório final: SM-COVID19 - Saúde mental em tempos de pandemia [Final report: SM-COVID19 - Mental health in the pandemic context]. Lisbon, Portugal: Instituto Nacional de Saúde Doutor Ricardo Jorge, IP.

Aventura Social (2020a). EsABE: Ecossistemas de aprendizagem e bem-estar-perfil dos agrupamentos que promovem o perfil do aluno à saída da escolaridade obrigatória [ESABE: Learning and wellbeing ecosystems - profile of school groups that promote student's competences at the end of schooling]. Lisbon, Portugal: FMH/DGE (Documento de trabalho DGE).

Aventura Social (2020b). EsABE: Ecossistemas de aprendizagem e bem-estar - trajetórias de evolução e recomendações [ESABE: Learning and wellbeing ecosystems - pathways and recommendations]. Lisbon, Portugal: FMH/DGE (Documento de trabalho DGE)

Bagcchi, S. (2020). Stigma during COVID-19 pandemic. The Lancet. Infectious diseases, 20(7), 782. https://doi.org/10.1016/ S1473-3099(20)30498-9

Branquinho, C., Kelly, C., Arevalo, L. C., Santos, A., \& Matos, M. G. (in prep). \#COVID\#BACKTOSCHOOL: A Mixed Study Based on the Voice of Portuguese Adolescents.

Branquinho, C., Kelly, C., Arevalo, L. C., Santos, A., \& Matos, M. G. (2020). "Hey, we also have something to say": A qualitative study of Portuguese adolescents' and young people's experiences under COVID-19. Journal of Community Psychology, 48(8), 2740-2752. https://doi.org/10.1002/jcop.22453.

Brooks, S., Webster, R, Smith, L., Woodland, L., Wessely, S., Greenberg, N., \& Rubin, G. (2020). The psychological impact of quarantine and how to reduce it: rapid review of the evidence. The Lancet, 395(10227), 912-920. https://doi.org/10.1016/S0140-6736(20)30460-8.

Bu, F., Steptoe, A., \& Fancourt, D. (preprint, 2021). Loneliness during lockdown: trajectories and predictors during the COVID-19 pandemic in 35712 adults in the UK. MedRxiv. https://doi.org/10.1101/2020.05.29.20116657.

Caldas de Almeida, J. M., Xavier, M., Cardoso, G., GonçalvesPereira, M., Gusmão, R., Corrêa, B., \& Silva, J. (2013). Estudo epidemiológico nacional de saúde mental: 1으 relatório. [Epidemiological national study on mental health: first report]. Faculdade de Ciências Médicas, Universidade Nova de Lisboa. Lisboa.

Ciampo, L., \& Ciampo, I. (2021) Social Isolation in Times of COVID-19: Effects on Adolescents' Mental Health. Asian Journal of Pediatric Research, 5 (1) 13-18. https://doi.org/10.9734/ajpr/2021/v5i130164.

Christakis, D. Cleve, W., \& Zimmerman, F. (2020). Estimation of US children educational attainment and years of life lost associated with primary schools closures during the coronavirus disease 2019 pandemic; JAMA Network Open, 3 
(11) 1-12. https://doi.org/10.1001/jamanetworkopen.2020.28786.

Dratva, J., Zysset, A., Schlatter, N., Wyl, A., Huber, M., \& Volken, T. (2020). Swiss university students' risk perception and general anxiety during the COVID-19 pandemic. International Journal of Environmental Research and Public Health, 17, 7433, doi: 10.3390/ijerph17207433.

Gaspar, T., Tomé, G., Ramiro, L., Almeida, A., \& Matos, M. G. (2020). Ecossistemas de aprendizagem e bem-estar: fatores que influenciam o sucesso escolar [Learning ecosystems and wellbeing: factors that influence school success]. Psicologia, Saúde \& Doenças, 21, 462-481. http://dx.doi.org/10.15309/20psd210221.

Gaspar, T., Cerqueira, A., Branquinho, C. \& Matos, M. G. (2018). The effect of a social-emotional school-based intervention upon social and personal skills in children and adolescents. Journal of Education and Learning, 7(6), 57-66. https://doi.org/10.5539/jel.v7n6p57.

Fancourt, D., Steptoe, A., \& Bu, F. (preprint, 2021). Trajectories of depression and anxiety during enforced isolation due to COVID-19: longitudinal analyses of 59318 adults in the UK with and without diagnosed mental illness. MedRxiv. https://doi.org/10.1101/2020.06.03.20120923.

Flugharty, M. \& Fancourt, D. (preprint, 2021). How have people been coping during the COVID-19 pandemic? Patterns and predictors of coping strategies amongst 26580 UK adults. PsyArXiv.

Fogg, B. J. (2019). Tiny habits: the small changes that change everything. NY: Penguin Random House.

Francisco, R., Pedro, M., Delvecchio, E., Pedro Espada, J., Morales, A., Mazzeschi, C., \& Orgilés, M. (2020). Psychological symptoms and behavioral changes in children and adolescents during the early phase of COVID-19 quarantine in three European countries. Frontiers in Psychiatry, 11, 1-14. https://doi.org/10.3389/fpsyt.2020.570164.

Jansen, D., Kosola, S., Arevalo, L. C., Matos, M. G., Boode, K., Saxena, S., \& Dratva, J. (2020). Child and adolescent health needs attention now, and in the aftermath of the COVID-19 pandemic. International Journal of Public Health, 65, 723725. https://doi.org/10.1007/s00038-020-01446-8,

Javed, B., Sarwer, A., Soto, E., \& Mashwani, Z. (2020). The coronavirus (COVID-19) pandemic's impact on mental health. International Journal of Health Plann Management, 35, 993996. https://doi.org/10.1002/hpm.3008.

Junior, L., Gaulac, C., Andrade, R., Amaral, R. (2021) Morbidity due to mental problems - analysis of time series in the previous period and during the COVID-19 pandemic. Research, Society and Development, 10, 2, 1-8. https://doi.org/10.33448/rsd-v10i2.12602.

Kowal, M., Coll-Martín, T., Ikizer, G., Rasmussen, J., Eichel, K., Studzińska, A., Koszałkowska, K., Karwowski, M., Najmussaqib, A., Pankowski, D., Lieberoth, A., \& Ahmed, O. (2020). Who is the most stressed during the COVID-19 pandemic? Data from 26 countries and areas. Applied Psychology: Health and Wellbeing, 12(4), 946-966. https://doi.org/10.1111/aphw.12234.

Lee, C., Cadigan, J., \& Rhew, I. (2020). Increases in loneliness among young adults during the COVID-19 pandemic and association with increases in mental health problems. Journal of Adolescent Health, 67, 714-717. https://doi.org/10.1016/j.jadohealth.2020.08.009.
Liu, J. J., Bao, Y., Huang, X., Shi, J., Lu, L. (2020). Mental health considerations for children quarantined with COVID 19. The Lancet: Child Adolescent health, 2(5), 347-349. https://doi.org/10.1016/S2352-4642(20)30096-1.

Loades, M. E., Chatburn, E., Higson-Sweeney, N., Reynolds, S., Shafran, R., Brigden, A., Linney, C., McManus, M. N., Borwick, C., \& Crawley, E. (2020). Rapid Systematic Review: The Impact of Social Isolation and Loneliness on the Mental Health of Children and Adolescents in the Context of COVID-19. Journal of the American Academy of Child and Adolescent Psychiatry, 59(11), 1218-1239.e3. https://doi.org/10.1016/j.jaac.2020. 05.009 .

Matos, M. G. (2021). \#IVDM - A última palavra é deles - A pandemia vista pelos sub-25 [\#IVDM - The last word is theirs - The pandemic seen by the under-25s] [Video File]. Youtube. https://www.youtube.com/watch?v=Y-iri9zbxUM.

Matos, M. G. (2020a). Adolescentes, as suas vidas, o seu futuro [Adolescents, their lives and their future]. Lisbon, Portugal: Fundação Francisco Manuel dos Santos.

Matos, M. G. (2020b). É mesmo importante? [Is it really important?]. Lisbon, Portugal: Ordem dos Psicólogos Portugueses.

Matos, M. G., Ramiro, L., Tomé, G., Branquinho, C., Almeida, A., Gaspar, S., Gaspar, T. (2021). Uma Educação e uma Escola com mais Saúde e Bem-Estar Psicológico: Contributos para o Desenho de Politicas Locais [An Education and School with More Health and Psychological Wellbeing: Contributions to the Design of Local Policies]. Odemira, Portugal: CM Odemira.

Matos, M. G., \& Aventura Social (2018). A saúde dos adolescentes portugueses após a recessão, relatório do estudo 2018 do HBSC/OMS em Portugal [The health of Portuguese teenagers after the recession, report from the 2018 HBSC / WHO study in Portugal] (ebook). www.aventurasocial.com.

Matos, M. G., Camacho, I., Reis, M., Tomé, G., Branquinho, C., \& Ramiro, L. (2017). Is truth in the eyes of the beholder? Or are Portuguese schools, as viewed by Portuguese pupils, mismatching with what the educational system offers? Vulnerable Children and Youth Studies, 13(2), 116-126. https://doi.org/10.1080/17450128.2017.1363447.

Mental Health Foundation (2020). Resilience across the UK during the coronavirus pandemic. https://www.mentalhealth. org.uk/coronavirus/resilience-across-uk-coronavirus-pandemic.

Munro, A. P. S., \& Faust, S. N. (2021). Addendum to: Children are not COVID-19 super spreaders: Time to go back to school. Archives of Disease in Childhood, 106(2), 19-20. https://doi.org/10.1136/archdischild-2020-319908.

Nearchou, F., Flinn, C., Niland, R., Subramanian, S., \& Hennessy, E. (2020). Exploring the impact of COVID-19 on Mental Health Outcomes in Children and Adolescents: a systematic review. International Journal of Environmental Research and Public Health, 17, 8479. https://doi.org/10.3390/ijerph17228479.

Orgilés, M., Espada, J., Delvecchio, E., Francisco, R., Mazzeschi, C., Pedro, M., \& Morales, A. (2021). Anxiety and Depressive Symptoms in Children and Adolescents during COVID-19 Pandemic: A Transcultural Approach. Psicothema, 33(1), 125130. https://doi.org/10.7334/psicothema2020.287.

O'Sullivan, K., Clark, S., McGrane, A., Rock, N., Burke, L., Boyle, N., Joksimovic, N., \& Marshall, K. (2021). A qualitative study of child and adolescent mental health during the COVID-19 pandemic in Ireland. International Journal of Environmental Research and Public Health, 18(3), 1-15. https://doi.org/10.3390/ijerph18031062. 
Paulino, M., Dumas-Diniz, R., Brissos, S., Brites, R., Alho, L., Simões, M., \& Silva, C. (2021). COVID-19 in Portugal: exploring the immediate psychological impact on the general population. Psychology, Health \& Medicine, 26(1), 44-55. https://doi.org/10.1080/13548506.2020.1808236

Ramiro, L., Reis, M., Matos, M.G., Diniz, J. A. (2014). Trends in adolescent sexual behavior, impact of information, and attitudes about HIV/AIDS in Portugal. Psychology, Health \& Medicine 19, 5: 614 - 624. https://doi.org/10.1080/13548 506. 2013.845299.

Reis, M., Ramiro, L., Matos, M.G., \& Diniz, J.A. (2013). Nationwide survey on HIV/AIDS knowledge, attitudes and risk behaviour in university students of Portugal. The Spanish Journal of Psychology, 16, e99, 1-10. http://dx.doi.org/ 10.1017/sjp.2013.100.

Ritz, D., O'Hare, G., \& Burgess, M. (2020). The Hidden Impact of COVID-19 on Child Protection and Wellbeing. London: Save the Children International.

Rosling, H., Rosling, O., \& Ronnlund, A. (2018). Factfulness - ten reasons we're wrong about the world - and why things are better than you think. Flexibell AB.

Salvaterra, F., \& Chora, M. (2021). O Que Pensam e o Que Sentem as Familias em Isolamento Social [What Families in Social Isolation Think and Feel]. Lisbon, Portugal: Instituto de Apoio à Criança - Marketing, Comunicação \& Projetos.

Sang, S., Wang, C., Espelage, D., Fenning, P., \& Jimerson, S. (2020). COVID-19 and school psychology: adaptations and new directions for the field. School Psychology Review, 49(4), 431-437. https://doi.org/10.1080/2372966X.2020.1852852.

Shevlin, M., McBride, O., Murphy, J., Gibson-Miller, J., Hartman, T. K., Levita, L., Mason, L., Martinez, A. P., McKay, R., Stocks, T. V. A., Bennett, K. M., Hyland, P., Karatzias, T., \& Bentall., R. P. (2020). Anxiety, depression, traumatic stress and COVID19 related anxiety in the UK general population during the COVID-19 pandemic. BJPsych Open, 6(6), e125. https://doi.org/10.1192/bjo.2020.109.

Schwegler, G. (2020). Shifting inequalities in student's lifestyles during the COVID pandemic. SGS/SSS Societé Suisse de Sociologie, 157, 31-33.

Singh, S., Roy, D., Sinha, K., Parveen, S., Sharma, G., \& Joshi, G. (2020). Impact of COVID-19 and lockdown on mental health of children and adolescents: a narrative review with recommendations. Psychiatry Research, 293(August), 113429. https://doi.org/10.1016/j.psychres.2020.113429.

Szaszi, B., Palinkas, A., Palfi, B., Szollosi, A., \& Aczel, B. (2018). A systematic scoping review of the choice architecture movement: toward understanding when and why nudges work. Journal of Behavioral ecision Making, 31(3), 355-366. https://doi.org/10.1002/bdm.2035.

Thaler, R., \& Sunstein, C. (2008). Nudge. Lisbon, Portugal: Oficina do Livro.
Tomé, G., Almeida, A., Ramiro, L., Gaspar, T., \& Matos, M. G. (2020). Intervention in schools promoting mental health and wellbeing: a systematic review. Global Journal of Community Psychology Practice, 11(4).

Tomé, G., Branquinho, C., Cerqueira, A., Matos, M. G. (2020). COVID-19, social distance and adolescents' risk behaviours, wellbeing and life satisfaction: a proxy study drawn from HBSC study. Análisis y Modificación de Conducta, 47(175).

Tomé, G., Matos, M. G., Gomes, P., Camacho, I., \& Gaspar, T. (2017). Promoção da saúde mental nas escolas - Projeto ES'COOL [Promotion of mental health in schools - ES'COOL Project]. Revista de Psicologia da Criança e do Adolescente, 8(1), 173- 184.

UNICEF (2020a). The impact of COVID-19 on the mental health of adolescents and youth (UNICEF Latin America and Caribbean). https://www.unicef.org/lac/en/ impact-covid-19mental-health-adolescents-and-youth.

UNICEF. (2020b). UNICEF Executive Director Henrietta Fore's remarks at a press conference on new updated guidance on school-related public health measures in the context of COVID-19. https://www.unicef.org/press-releases/unicef-executive-director-henrietta-fores-remarks-press-conferencenew-updated.

UNICEF. (2020c). Policy brief: the impact of COVID-19 on children. UNICEF. United Nations 1-17. https://news.un.org/en/ tags/unicef.

Venkatesh, A., \& Edirappuli, S. (2020). Social distancing in covid19: what are the mental health implications?. British Medical Journal (Clinical research ed.), 369, m1379. https://doi.org/ 10.1136/bmj.m1379.

Viner, R., Russell S., Croker, H., Packer, J., Ward, J., Stansfield, C., Mytton, O., Bonell, C., \& Booy, R. (2020). School closure and management practices during coronavirus outbreaks including COVID-19: a rapid systematic review. Lancet Child Adolescent Health, 4, 397-404. https://doi.org/10.1016/ S2352-4642(20)30095-X

Vizard, T., Sadler, K., Ford, T., Newlove-Delgado, T., McManus, S., Marcheselli, F., Davies, J., Williams, T., Leach, C., Mandalia, D., \& Cartwright, C. (2020). Mental Health of Children and Young People in England, 2020 Wave 1 follow up to the 2017 survey. United Kingdom, Surrey: NHS.

WHO (2018) Standards for Health Promoting Schools, Copenhagen: WHO office.

WHO (2020a) Global Standards and Indicators for Health Promoting Schools: Copenhagen: WHO office.

WHO (2020b) Implementation Guidance for Health Promoting Schools, Copenhagen: WHO office.

Zhou, J., Liu, L., Xue, P., Yang, X. \& Tang, X. (2020). Mental health response to the COVID-19 outbreak in China. American Journal of Psychiatry, 177(7), 574-575. https://doi.org/ 10.1176/appi.ajp.2020.20030304. 